\title{
Serendipity: the myth of delayed lightning strikes
}

\author{
Minh-Hoang Nguyen \\ Centre for Interdisciplinary Social Research \\ Phenikaa University \\ Yen Nghia, Ha Dong, Hanoi 100803, Vietnam
}

December 02, 2021

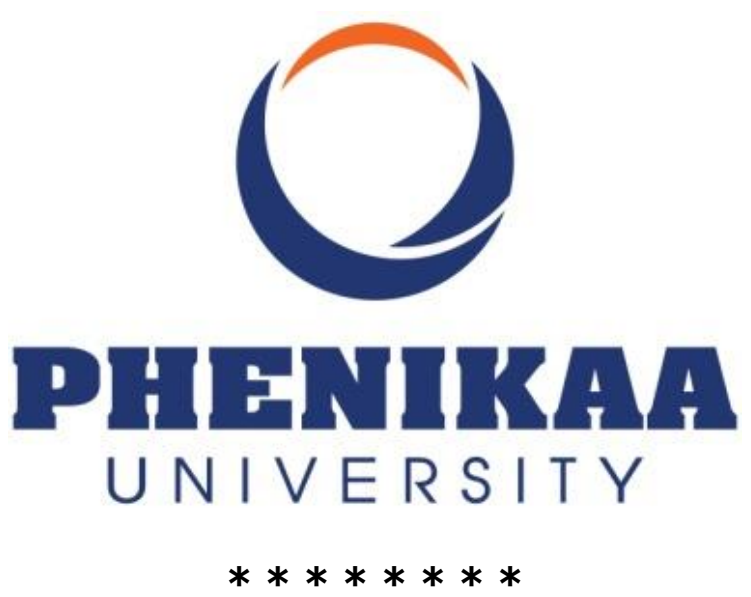

Many years ago, Prof. Nancy K. Napier and Prof. Vuong Quan Hoang came up with several important research ideas, which have since led to their published works and continued to help us grow while pursuing our own research career paths.

Some exemplary ideas include serendipity as a strategic (or competitive) advantage, Aha! moment, disciplined processes of creativity, and mindsponge processes [1-3]. These have recently been referred to and applied by numerous research publications worldwide. But I will only focus on the serendipity strike, which I personally experienced more than once, for instance, the development of BMF [4] and the suicidal ideation mechanism [5], and observed from my mentor [6].

The serendipity-based creativity process in their conceptual development papers has been particularly appealing for me due to its power to harness unexpectedly useful information as a strategic advantage in business operations, technological innovations, and scientific discoveries. Their metaphor for the serendipity process resembles the radar technology for detecting fast-flying objects. Nonetheless, others refer to it as "lightning strikes". So I call it a serendipity strike. 
On its face value, one might think of it as a sudden idea, which results in an unexpected value, at an unexpected place, and at an unexpected time. People tend to like this mysterious imagination in part because it causes them to think of fantasy. I used to think it this way, too, until I embarked on the process of developing the BMF applications [7].

While it is true that those "unexpected" are critically important, the idea that a magic touch can solve it all is wrong. The strategic value of serendipity can only be realized when some specific conditions are met [8].

First, many preparatory works need to be done, including a prolonged process of thinking about the problem deeply.

Second, various aspects of disciplines, sometimes boring ones, will have to be institutionalized.

Third, for a person to be ready for "unexpected values," it is required that an alien (but potentially truly crucial) value must not be rejected before it is fully evaluated. And this has something to do with the mindsponge mechanism [9], or more specifically, the mindsponge culture [10].

I will stop here to save time since these three conditions suffice to support the subsequent argument:

The myth of serendipity strikes is not mysterious. They are prolonged processes that wait for the final critical piece of information to complete a satisfactory solution, be it a mathematical solution, scientific discovery, or radical technology innovation.

More interestingly, most lightning strikes are not occurring at lightning speeds. It seems that the arrival time and quantity (if quantifiable) of useful information are stochastic and unpredictable. The best we can do is to expect they might happen. So perhaps the best trick is always carrying a small notepad and a pencil with us. In fact, we will have little choice but to wait for a delayed lightning strike. Unfortunately, we have no tool to predict how long the delay will be.

The true myth is: We do not know how many times in the past we have missed the valuable serendipity moments!

Why this is a true myth will be my homework for many years to come. If serendipity works (I hope so), then that true myth will no longer be a myth and will become an important discovery instead. 


\section{Acknowledgement}

I would like to send my gratitude to Prof. Vuong Quan Hoang for granting me this valuable idea.

\section{References}

[1] Napier NK, Vuong QH. (2013). Serendipity as a strategic advantage?. In Wilkinson (ed) Strategic Management in the 21st Century (pp. 175-199). Westport, CT: Praeger/ABC-Clio.

[2] Vuong QH. (2016). Global mindset as the integration of emerging socio-cultural values through mindsponge processes: A transition economy perspective. In: J. Kuada (ed.) Global Mindsets: Exploration and Perspectives (pp. 109-126). London: Routledge.

[3] Vuong QH, Napier NK. (2014). Making creativity: the value of multiple filters in the innovation process. International Journal of Transitions and Innovation Systems, 3(4), 294-327.

[4] Nguyen MH, Le TT. (2021). Bayesian Mindsponge Framework. OSF Preprints. Retrieved from: https://osf.io/b4uny

[5] Nguyen MH, Le TT, Nguyen HKT, Ho MT, Nguyen HTT, Vuong QH. (2021). Alice in Suicideland: Exploring the suicidal ideation mechanism through the sense of connectedness and help-seeking behaviors. International Journal of Environmental Research and Public Health, 18(7), 3681.

[6] Vuong QH. (2021). Western monopoly of climate science is creating an eco-deficit culture. Economy, Land \& Climate Insight. Retrieved from: https://elcinsight.org/western-monopoly-of-climate-science-is-creating-an-ecodeficitculture/

[7] Nguyen MH. (2021). The serendipitous moment leading to the discovery of the Bayesian Mindsponge Framework. OSF Preprints. Retrieved from: https://osf.io/x5pf4/

[8] Nguyen MH. (2021). From mindsponge process to discovery. OSF Preprints. Retrieved from: https://osf.io/jfnze/

[9] Nguyen MH, Vuong QH, Ho MT, Le TT. (2021). Mindsponge mechanism. SSRN. Retrieved from: https://papers.ssrn.com/sol3/papers.cfm?abstract id=3887262 
[10] Nguyen MH. (2021). Mindsponge culture. SSRN. Retrieved from: https://papers.ssrn.com/sol3/papers.cfm?abstract id=3972996 